\title{
As (po)éticas do espaço: mulheres negras e exposições museológicas
}

Mulheres negras e museus de Salvador: diálogo em preto e branco. FLORES, Joana.

Salvador: Fundo de Cultura, 2017, $152 \mathrm{p}$.

Justifico a construção dessa obra como munição em forma de coragem para debater sobre o não lugar das memórias dessas mães, irmãs, tias e esposas, nos museus de tipologia histórica em Salvador. Se for para falar de escravidão em museus, que falem de prisão, falem de lutas e de injustiças. Não nos coloquem como elementos fortuitos de uma estereotipização de corpos que tiveram donas com nomes e sobrenomes. Joana Flores (2017, p. 21)

\begin{abstract}
O trecho em epígrafe revela um dos muitos incômodos de grande parte das mulheres negras brasileiras ao se depararem com suas representações no campo de produção simbólico. Problematiza o lugar das memórias femininas e de suas intersecções de raça, classe e região ao se tornar munição para a promoção de um conjunto de desrecalques visando desnaturalizar práticas opressoras. Nesse sentido, para além da denúncia de como os corpos das mulheres negras continuam sendo representados nas exposições dos museus de tipologia histórica em Salvador-BA, trata-se de uma voz dissonante no campo da Museologia ao apontar como a própria disciplina também contribuiu para silenciar essa temática.

As mulheres ainda continuam personagens silenciadas em grande parte das exposições museológicas e seu legado ainda necessita ser revisitado no cenário da museologia brasileira. O livro de Joana Flores problematiza o modo como os indivíduos e as instituições, ao contribuírem para a fabricação de imortalidades e perpetuação de legados monumentalizadores, manipulam essas narrativas ocasionando silêncios e silenciamentos de determinados aspectos da participação das mulheres - especialmente das mulheres negras - ou, em outras palavras, esquecimentos. São questões que desembocam em embates de uma política da memória que permeia a constituição das narrativas. Nesse sentido, contribui para que nos enveredemos pelos rastros/restos que sobraram da trajetória e da história oficial no intuito de esboçar outra história e inventar o presente, conforme esclareceu Jeanne Marie Gagnebin
\end{abstract}


(2006) quando destacou que as tentativas de apagar os indícios criam involuntariamente rastros que permitem recuperar fragmentos de uma determinada trajetória social, ou seja, resistir à ação silenciadora do tempo e da história: ao "apagar rastros, [o sujeito] deixa outros que não quis" (GAGNEBIN, 2006, p. 115). Seria um dos efeitos da atividade de rememorar:

Tal rememoração implica uma certa ascese da atividade historiadora, que, em vez de repetir aquilo de que se lembra, abre-se aos brancos, aos buracos, ao esquecido e ao recalcado, para dizer, com hesitações, solavancos, incompletude, aquilo que ainda não teve direito nem à lembrança nem às palavras. A rememoração também significa uma atenção precisa ao presente, particularmente a estas estranhas ressurgências do passado no presente, pois não se trata somente de não se esquecer do passado, mas também de agir sobre o presente. A fidelidade ao passado, não sendo um fim em si, visa à transformação do presente. (GAGNEBIN, 2006, p. 91)

A questão é que são esses mesmos mecanismos seletivos que iluminam percursos, nomes e legados, sendo utilizados para a invenção do anonimato, a fabricação da desimportância, a instituição de vazios. Por isso Michele Asmar Fanini (2009) reconhece que investigar presenças consiste em um estudo das ausências, fruto de uma engenhosa operação. Dessa forma, os silêncios podem sinalizar "não sua inexistência de fato, mas sua presença como parte do 'inenarrável', estando situadas, por constrições várias, 'fora do acontecimento'" (FANINI, 2009, p. 16). Interditos que no itinerário de Joana Flores podem ser reconhecidos como rastros, indícios que possibilitaram ler os testemunhos a contrapelo, problematizando, inclusive, as intenções de quem os construiu. Questões mais evidentes no caso das trajetórias de mulheres que tiveram sua atuação (ou parte dela) esquecida na "política da história", compreendida como jogos de poder nos exercícios de registro/escrita da história (Joan SCOTT, 2002).

Por essa razão, a escolha por analisar a representação das mulheres nos museus de tipologia histórica tenha sido tão acertada. Apesar de sua inegável presença e do decisivo papel de mediadora cultural, historicamente as mulheres estiveram excluídas das narrativas oficiais da história e da memória nacionais (Rita Terezinha SCHMIDT, 2000). Na maioria das vezes, quando lembradas, não receberam a mesma avaliação dispensada aos homens e seus nomes foram apenas citados entre uma exaustiva enumeração de autores, cortesia que reforça a ideia de excepcionalidade a uma regra masculina. Para tanto, concordamos com Kátia da Costa Bezerra (2007) quando destacou as estratégias de algumas mulheres para romper com práticas discursivas opressivas e alcançar um lugar de fala no século XX. Tais ações visaram distanciar de leituras hegemônicas do passado, apresentando outras vozes que reafirmam diferenças. Para a pesquisadora, tais mulheres, ao se dedicarem a uma reescrita da memória a partir do feminino, do cotidiano e de suas memórias pessoais, construíram uma memória em falsete.

O mergulho em aspectos da economia simbólica dos acervos se torna uma das possibilidades para explicitar vinculações hierarquizantes entre a trajetória dos agentes responsáveis por sua fabricação/consagração, nos moldes apresentados por Regina Abreu (1996), e os registros produzidos, estratégias de demarcação e ocultamento. Os objetos e documentos, versões e construções acerca de acontecimentos reais, podem se transformar em "fonte poderosa de legitimação, com todas as incongruências aí subjacentes, que envolvem desde os silenciamentos, ofuscamentos e distorções, até a supervalorização dos que detêm maior capital social" (FANINI, 2009, p. 6), daí porque investigar as presenças consiste, ao mesmo tempo, em um estudo das ausências.

No caso das mulheres, essas práticas assumem outra preocupação na medida em que reconhecemos as estratégias forjadas em prol das clivagens de gênero. De acordo com a clássica expressão de Michelle Perrot (2005), as mulheres são os "silêncios da história" (PERROT, 2005, p. 9). Segundo a autora, essa aproximação ganha fôlego na medida em que relatamos irrupções de presenças e de falas femininas em locais até então proibidos 
ou não familiares e que, ainda hoje, são envoltas por muitas zonas mudas, relacionadas à partilha desigual dos traços, da memória e da história. Situação que pode ser visualizada quando observamos suas representações em exposições museológicas, conforme explicitou Aida Rechena (2011) em análises sobre as imagens das mulheres nos museus portugueses:

A maior parte dos museus constrói um discurso sobre as mulheres que corresponde à categorização social dominante com recurso aos bens patrimoniais existentes no acervo. Limitando-se a expor os objetos sem os problematizar ou interrogar, os museus permitem às obras expostas, por um lado transmitir as categorias de mulher contidas nelas à priori e por outro permitem ao leitor descodificar as obras com recuso às representações sociais dominantes, que sabemos serem tendencialmente desvalorizadoras do papel da mulher, mantendo as hierarquias das relações de gênero. A estas duas circunstâncias acresce o facto dos discursos expositivos serem majoritariamente afirmativos e declarativos e por esse facto homologatórios, inviabilizando a possibilidade de interpretações alternativas. Não se verifica nas exposições estudadas o aproveitamento das imagens de mulheres existentes nos acervos e nas exposições para refletir sobre a situação atual das categorias de mulheres ali presentes: mães donas de casa, operárias, trabalhadoras do meio rural, fadistas, atrizes. Este facto merece-nos uma observação: se os museus estivessem previamente a trabalhar com a categoria gênero, teriam representado estas mesmas categorias de mulher, mas teriam incluído uma análise da sua relação com os homens, do seu papel na sociedade, teriam personalizado determinadas mulheres em vez de abordar a categoria de maneira uniforme, universal e definitiva. (RECHENA, 2011, p. 352-353).

Na verdade, problematizar os silenciamentos, as naturalizações ou a fabricação da excepcionalidade da presença das mulheres nos museus consiste em um importante campo de investigação que ainda é pouco explorado no cenário da museologia. Trata-se de vislumbrar novas poéticas do espaço, questionando como as (po)éticas e as políticas da memória contribuem para espacializar determinadas versões, solidificando narrativas e combatendo discursos dissidentes para além dos sótãos, dos porões e dos espaços onde se convencionou enquadrar as memórias das mulheres. Desse modo, o título desta resenha não dialoga com a perspectiva fenomenológica proposta por Gaston Bachelard (2008), mas com uma leitura que evidencia as disputas, as hierarquizações e as construções de poder empreendidas nos e a partir de determinados corpos e o modo como foram e são narrados no espaço público. Corpos cuja presença em espaços de poder, a exemplo dos museus analisados por Joana Flores - e não apenas eles - continuam sendo disciplinadas sob as luzes e as vitrines da misoginia e do racismo.

É especialmente por efetuar esse duplo desrecalque que a pesquisa de Joana Flores apresenta outra configuração no cenário dos estudos sobre museus e da própria museologia. Ao promover um conjunto de diálogos em preto e branco, a museóloga oferece uma instigante palheta com múltiplos tons que denunciam o modo como as mulheres negras continuam sendo representadas nos museus brasileiros, partindo dos museus históricos de Salvador como metonímia. Joana Flores, por sentir na própria pele e mobilizar a herança dessas mulheres representadas nas exposições, evidencia o modo como as mulheres negras constituem os silêncios entre os silêncios da história, ocupando uma posição ainda mais desprestigiada. A pesquisa de campo sublinhou que quando estão presentes ocupam a posição de coadjuvantes, muitas vezes reforçando a associação entre mulheres negras e escravização e reproduzindo discursos racistas.

Essa percepção inovadora, a despeito das escassas pesquisas sobre o lugar das mulheres negras nas exposições museológicas, foi construída a partir da própria trajetória de Joana Flores. É uma mulher negra, pesquisadora e museóloga, cuja trajetória de enfrentamentos no campo de produção simbólico se deparou com muitas das questões suscitadas no livro. Nesses moldes, outra contribuição da obra é demonstrar eixos analíticos capazes de enfrentar com paixão e rigor o desafio da proximidade. Estranhar o familiar possibilitou que a reflexão sobre a singularidade de uma época e de determinadas vidas com ideais comuns constituísse um atalho para a instituição de um texto perpassando a 
história das ideias. Há algumas décadas os estudos de histórias de vida e de grupos tornaram-se matéria importante para as ciências sociais por esboçarem as interações dos indivíduos, percebidos como sujeitos de ação social tecida a partir de uma rede de significados. Os cientistas sociais passam a visualizar os indivíduos como intérpretes de mapas e códigos socioculturais, fator que enfatizaria a dinamicidade da vida social e instituiria pontes entre os níveis micro e macro (Gilberto VELHO, 2003).

Isso ganha ênfase quando Joana Flores institui, ela própria, uma memória em falsete ao mobilizar e ao ocupar um espaço de poder no campo científico brasileiro. Operação metapoética que evidencia seus próprios enfrentamentos no espaço científico e, ao mesmo tempo, denuncia e oferece ferramentas teórico-metodológicas para compreendermos o lugar das mulheres negras nos jogos de poder dos espaços museais. Trata-se, sem dúvida, de um trabalho com múltiplos comprometimentos e, portanto, atravessado por muitas (po)éticas e políticas da memória. Dessa maneira, reverbera um conjunto de dramaticidades que potencializa questões para além dos espaços museológicos.

A pesquisadora, após destacar o papel da teoria museológica na construção de discursos sobre exposições, identidades e raças e os processos de significação na representação do objeto museológico, analisa essas hierarquizações em sete exposições de longa duração em museus de tipologia histórica em Salvador. Por fim, se detém na exposição do Museu do Traje e do Têxtil, concebendo-a como metáfora e metonímia da representação dominante sobre as mulheres negras nos museus. Na verdade, o livro de Joana Flores repercute a pergunta formulada por Glória Anzaldúa (2000) sobre a importância do ato de escrever:

Por que sou levada a escrever? Porque a escrita me salva da complacência que me amedronta Porque não tenho escolha. Porque devo manter vivo o espírito de minha revolta e a mim mesma também. Porque o mundo que crio na escrita compensa o que o mundo real não me dá. No escrever coloco ordem no mundo, coloco nele uma alça para poder segurá-lo. Escrevo porque a vida não aplaca meus apetites e minha fome. Escrevo para registrar o que os outros apagam quando falo, para reescrever as histórias mal escritas sobre mim, sobre você. Para me tornar mais íntima comigo mesma e consigo. Para me descobrir, preservar-me, construir-me, alcançar autonomia. Para desfazer os mitos de que sou uma profetisa louca ou uma pobre alma sofredora. Para me convencer de que tenho valor e que o que tenho para dizer não é um monte de merda. Para mostrar que eu posso e que eu escreverei, sem me importar com as advertências contrárias. Escreverei sobre o não dito, sem me importar com o suspiro de ultraje do censor e da audiência. Finalmente, escrevo porque tenho medo de escrever, mas tenho um medo maior de não escrever. (ANZALDÚA, 2000, p. 232)

O fato é que o ato políico de Joana Flores ao escrever sobre o modo como seu sexo e sua raça vêm sendo representados por seus colegas de profissão nos museus de Salvador consiste em uma forma de mobilizar o pensamento colonialista e colonizador que ainda impera no campo da ciência e dos museus. A obra se torna um convite ao estudo e à valorização das memórias e trajetos das mulheres negras. Mulheres que, em movimento, se organizaram e ampliaram o caleidoscópio de vozes e cores não apenas em prol da constituição de um lugar de fala dissonante, mas de um lugar onde suas vozes em uníssono adquirissem ressonância. Constitui em convite para refletirmos sobre a representação de minorias nem sempre numéricas em espaços de produção simbólico e um esforço para novas pesquisas que, a partir da obra, também questionem a abstração universal "mulher negra" que encobre inúmeras diferenças sociais.

\section{Referências}

ABREU, Regina. A fabricação do imortal: memória, história e estratégias de consagração no Brasil. Rio de Janeiro: Rocco, 1996.

ANZALDÚA, Gloria. "Falando em línguas: uma carta para as mulheres escritoras do terceiro mundo". Revista Estudos Feministas, Florianópolis, v. 8, n. 1, p. 229-236, jan. 2000. 
BACHELARD, Gaston. A poética do espaço. 2. ed. Trad. de Antônio de Pádua Danesi. São Paulo: Martins Fontes, 2008.

BEZERRA, Kátia da Costa. Vozes em dissonância: mulheres, memória e nação. Florianópolis: Mulheres, 2007.

FANINI, Michele Asmar. Fardos e fardões: mulheres na Academia Brasileira de Letras (18972003). Tese (Doutorado em Sociologia) - Faculdade de Filosofia, Letras e Ciências Humanas, Universidade de São Paulo, 2009.

FLORES, Joana. Mulheres negras e museus de Salvador: diálogo em preto e branco. Salvador: Fundo de Cultura, 2017.

GAGNEBIN, Jeanne Marie. Lembrar, escrever, esquecer. São Paulo: Ed. 34, 2006.

PERROT, Michelle. As mulheres ou os silêncios da história. Trad. de Viviane Ribeiro. Bauru, SP: EDUSC, 2005.

RECHENA, Aida Maria Dionísio. Sociomuseologia e gênero: imagens da mulher em exposições de museus portugueses. Tese (Doutorado em Museologia), Universidade Lusófona de Humanidades e Tecnologias, Lisboa, 2011.

SCHMIDT, Rita Terezinha. "Mulheres reescrevendo a nação". Revista Estudos Feministas, v. 8, n. 1, p. 84-97, 2000.

SCOTT, Joan Wallach. A cidadã paradoxal: as feministas francesas e os direitos do homem. Trad. de Élvio Antônio Funck. Florianópolis: Mulheres, 2002.

VELHO, Gilberto. "O desafio da proximidade". In.: VELHO, Gilberto; KUSCHNIE, Karina (Orgs.). Pesquisas urbanas: desafios do trabalho antropológico. Rio de Janeiro: Jorge Zahar Editor, 2003, p. 11-19.

[Recebida em 02/09/2017

e aceita em 29/01/2018]

Clovis Carvalho Britto'

'Universidade de Brasília, Faculdade de Ciência da Informação, Brasília, DF, Brasil

Clovis Carvalho Britto (clovisbritto5@hotmail.com) é Pós-Doutor em Estudos Culturais pela Universidade Federal do Rio de Janeiro. Doutor em Sociologia pela Universidade de Brasília e Doutorando em Museologia pela Universidade Lusófona de Humanidades e Tecnologias, Lisboa, Portugal. Professor no Curso de Museologia da Universidade de Brasília e no Programa de Pós-Graduação em Museologia na Universidade Federal da Bahia.

(iD) 0000-0001-6267-544X 